Revista Brasileira de Agricultura Irrigada v.12, nº.5, p. 2877 - 2889, 2018

ISSN 1982-7679 (On-line)

Fortaleza, CE, INOVAGRI - http://www.inovagri.org.br

DOI: $10.7127 /$ rbai.v12n500849

Protocolo 849.18 - 21/12/2017 Aprovado em 30/09/2018

\title{
AVALIAÇÃO DE NPK E DOSES DE BIOFERTILIZANTE ORGÂNICO NO CRESCIMENTO DO FEIJÃO-CAUPI
}

\author{
Jhonata Santos Santana ${ }^{1}$, Mateus Leite Feitoza ${ }^{2}$ Gustavo Costa de Oliveira $^{3}$, Wilson Araújo \\ da Silva ${ }^{4}$
}

\section{RESUMO}

O estudo foi realizado na cidade de Governador Edson Lobão, Estado do Maranhão, e propôs avaliar os parâmetros: altura média, massa fresca da parte aérea, massa seca da parte aérea, massa seca da raiz, número de folhas/planta e número de nódulos, em função da adubação química e da aplicação de doses de biofertilizante associado com rizóbios (Bradyrhizobium sp.) em plantas de feijão-caupi. Utilizou-se o delineamento inteiramente casualizado (DIC), composto por seis doses de biofertilizante (10\%, 20\%, 30\%, 50\%, 70\% e 90\%), adubação com NPK e testemunha, totalizando 8 tratamentos e 7 repetições. Verificou-se que houve resposta significativa dos tratamentos estudados em nível de $5 \%$ de probabilidade para a maior parte dos parâmetros avaliados. A dose de 50\% de biofertilizante apresentou melhor desempenho para as variáveis altura de plantas, massa seca da raiz, e número de folhas. A dose de $70 \%$ proporcionou valor máximo para as variáveis massa fresca da parte aérea e massa seca da parte aérea. No comprimento de raiz o melhor desempenho foi obtido na dose de 30\%. O NPK e as doses de biofertilizante não afetaram de forma significativa o número de nódulos por planta, que variou de 162,57 a 60 unidades, onde o maior valor foi obtido no tratamento NPK. A partir dos resultados obtidos no presente trabalho pode-se concluir que a aplicação do composto orgânico líquido favoreceu aumento de desempenho para a maior parte dos parâmetros avaliados na cultura de feijão caupi especialmente nas doses de 50 e $70 \%$ de biofertilizante.

Palavras-chave: Bradyrhizobium sp., composto orgânico, desempenho.

\section{EVALUATION OF NPK AND DOSES OF ORGANIC BIOFERTILIZER IN THE GROWTH OF CAUPI BEANS}

\footnotetext{
ABSTRACT

${ }^{1}$ Graduado em Engenharia Agronômica, Bolsista BATI-II UEMASUL, Imperatriz - Maranhão, Email: agro.starf@gmail.com

${ }^{2}$ Graduado em Engenharia Agronômica, UEMASUL, Imperatriz - Maranhão, Email: mateuslf.agro@hotmail.com

${ }^{3}$ Mestrando em Agricultura e Ambiente, UEMA, campus São Luís-Maranhão

${ }^{4}$ Prof. Doutor UEMASUL, campus Imperatriz- Maranhão
} 
The study was carried out in the city of Governador Edson Lobão, State of Maranhão, and proposed to evaluate the parameters: mean height, fresh shoot mass, dry shoot mass, root dry mass, number of leaves / plant and number of nodules , as a function of chemical fertilization and the application of doses of biofertilizer associated with rhizobia (Bradyrhizobium sp.) in cowpea plants. A completely randomized design (DIC) was used, consisting of six doses of biofertilizer (10\%, 20\%, 30\%, 50\%, 70\% and 90\%), fertilization with NPK and control, totaling 8 treatments and 7 replicates. It was found that there was a significant response of the treatments studied at a $5 \%$ probability level for most of the evaluated parameters. The dose of $50 \%$ of biofertilizer presented better performance for the variables plant height, root dry mass, and number of leaves. The $70 \%$ dose provided maximum value for the variables fresh shoot mass and dry shoot mass. In the root length the best performance was obtained in the dose of $30 \%$. NPK and biofertilizer doses did not significantly affect the number of nodules per plant, ranging from 162.57 to 60 units, where the highest value was obtained in the NPK treatment. From the results obtained in the present work it can be concluded that the application of the liquid organic compound favored an increase in performance for most of the parameters evaluated in cowpea, especially at 50 and $70 \%$ biofertilizer doses.

Keywords: Bradyrhizobium sp., organic compound, performance.

\section{INTRODUÇÃO}

O feijão caupi, destaca-se como uma cultura de grande importância socioeconômica, sendo a principal fonte de proteína vegetal para a maior parte da população, diante disso a produção desta cultura tem sido insuficiente para suprir a demanda do consumo. Segundo CONAB (2018) no Maranhão, a safra 2017/2018 apresentou uma área semeada de 37,4 mil hectares, o que representa um aumento de $2,7 \%$ em relação à safra passada.

A exploração econômica do feijão caupi é realizada por diversos tipos de produtores, em várias regiões do país com diferentes níveis tecnológicos. A agricultura familiar é apontada como a grande responsável pelo cultivo do feijão no Brasil (SILVA; WANDER, 2013).

Dada a grande importância do feijão-caupi em proporcionar alimento, gerando renda para as populações rurais e urbanas das regiões Norte e Nordeste, o seu consumo está sendo expandido para as regiões Centro-Oeste e Sudeste do Brasil (FREIRE FILHO et al., 2011). Conforme Barros et al. (2013), essa cultura é uma alternativa social e econômica e a preferida pelos agricultores familiares da região Meio-Norte do Brasil. De acordo com Beltrão Júnior et al., 2012 o emprego de compostos orgânicos na produção agrícola é uma prática adotada no mundo inteiro e a eficiência da adubação orgânica depende do sistema e da forma como se executa o processo de preparo do mesmo e do tipo de matéria prima utilizada, podendo ocorrer elevadas variações de qualidade. Os efeitos positivos da adubação orgânica devem-se não somente ao fornecimento de nutrientes, mas também a sua atuação na melhoria da capacidade de trocas de cátions, resultando em disponibilidade de nutrientes por um maior período de tempo (SILVA et al., 2012). Assim, o emprego de adubos orgânicos como o biofertilizantes é uma boa alternativa à adubação convencional quando esta é onerosa, podendo proporcionar aumento de produtividade e reduzir o custo com fertilizantes SEDIYAMA et al. (2014). Diversos trabalhos relatam o aproveitamento da matéria orgânica após a biodigestão para diversos fins como fertilizantes agrícolas, alimentos para animais e acondicionantes para o solo (RODOLFO JUNIOR et al., 2009).

As inoculações pela utilização de biofertilizante associado à inoculante de rizóbios da espécie (Bradyrhizobium sp.) são alternativas importantes em relação aos fertilizantes químicos em sistemas de produção sustentáveis (BUCHER; REIS, 2008). Além disso, melhorando-se o desempenho simbiótico, pode-se, da mesma forma que ocorre com a soja, dispensar a necessidade do uso de adubos nitrogenados para obtenção de maiores rendimentos (RUMJANEK et al., 2005). 
Diante do exposto, o trabalho se propõe a avaliar as seguintes variáveis: altura média (ALT), massa fresca da parte aérea (MFPA), massa seca da parte aérea (MSPA), massa seca da raiz (MSR), número de folhas/planta (NF), número de nódulos / planta (ND), em função da aplicação de doses de biofertilizante, produzido através da fermentação de esterco de aves por meio de rizóbios da espécie (Bradyrhizobium $s p$.) e adubação NPK.

\section{MATERIAL E MÉTODOS}

\section{Caracterização geográfica e climática da região do estudo}

O presente estudo foi realizado na região Sudoeste do estado do Maranhão mais precisamente na cidade de Governador Edson Lobão, no estado do Maranhão (Latitude: $5^{\circ}$ 39' 18” S; Longitude: $47^{\circ} 23^{\prime} 27^{\prime \prime}$ W e Altitude de $160 \mathrm{~m}$. O clima é classificado pelo método de Köpen como do tipo (Aw), tropical quente e úmido, com precipitações mal distribuídas, e duas estações: a da chuva, que vai de dezembro a abril, e a da seca, que vai de maio a novembro (CLIMATE-DATA, 2018).

\section{Delineamento experimental}

O experimento foi realizado em uma casa de vegetação com área útil de $24 \mathrm{~m}^{2}$, e o delineamento experimental utilizado foi 0 inteiramente casualizado (DIC) composto de 8 tratamentos e 7 repetições (56 vasos de polietileno de $11 \mathrm{dm}^{3}$ ). Foi utilizada a cultivar de feijão-caupi BRS Novaera, disponibilizada pela empresa de Sementes Tomazzeti Ltda. Os tratamentos consistiram de seis doses de biofertilizante (10\%, 20\%, 30\%, 50\%, 70\% e 90\%), adubo NPK (de acordo com a dose recomendada, baseada na análise de solo) e testemunha.

T1- Com adubo NPK e inoculação viasemente; $\mathrm{T}_{2}-10 \%$ de biofertilizante; $\mathrm{T}_{3}$ - $20 \%$ de biofertilizante; $\mathrm{T}_{4}$ - $30 \%$ de biofertilizante; $\mathrm{T}_{5}$ $50 \%$ de biofertilizante; $\mathrm{T}_{6}-70 \%$ de biofertilizante; $\mathrm{T}_{7-}$ 90\% de biofertilizante; $\mathrm{T}_{8-}$ Sem biofertilizante/sem adubo NPK, assim contendo 7 repetições cada tratamento. O tratamento 8 “testemunha” não recebeu nem biofertilizante orgânico e nem adubação mineral com NPK, sendo os vasos preenchidos somente com solo.

\section{Instalação e condução do experimento}

Para a produção do biofertilizante orgânico utilizou-se esterco de aves fresco, o qual foi adquirido em uma granja de aves localizada no município de Governador Edson Lobão-MA. Os três litros (3L) de inoculantes utilizados no experimento eram pertencentes a estirpe de Bradyrhizobium sp.

Para produção do biofertilizante foi utilizado resíduo orgânico parcialmente decomposto (12 kg de esterco de aves) e 3 litros de inoculantes líquido do estirpe Bradyrhizobium sp, onde foram misturados nas proporções de $20 \%$ de esterco aves e $5 \%$ de microrganismo e o restante foi completado com água.

A técnica de produção do biofertilizante utilizada neste trabalho foi baseada nos estudos de Bucher e Reis (2008) que demostram a importância do uso de biofertilizantes contendo bactérias diazotróficas como alternativa de para o aumento da eficiência de inoculação. Assim, este biofertilizante foi produzido da seguinte forma: $12 \mathrm{~kg}$ de esterco de aves que foram colocados em um tambor plástico de 60 litros em seguida foi adicionado 3 litros de inoculante líquido e o restante do volume do tambor foi completado com água, depois este tambor foi tampado, onde mistura esterco-inoculante ficou isolada para favorecer a ação decompositora das bactérias sobre o composto orgânico.

Após 30 dias foi obtido o "fertilizantebiológico" o qual o seu sobrenadante foi coletado e utilizado para compor as soluções utilizadas em cada um desses tratamentos, sendo para o tratamento 2 (10\% de sobrenadante e $90 \%$ de água), tratamento 3 ( $20 \%$ de sobrenadante e $80 \%$ de água), tratamento $4 \quad(30 \%$ de sobrenadante e $70 \%$ de água), tratamento 5 (50\% de sobrenadante e $50 \%$ de água), tratamento 6 (70\% de sobrenadante e 30\% de água), tratamento 7 (90\% de sobrenadante e $10 \%$ de água). Estas soluções foram utilizadas para irrigar os vasos contendo solo uma vez por semana, até a sétima semana após a germinação. 
Abaixo segue-se a descrição dos tratamentos utilizados neste experimento.

O tratamento 1 foi feita a inoculação via semente e adubação com NPK de acordo com a recomendação da análise de solo. Nos tratamentos 2, 3, 4, 5, 6 e 7 foi realizada a adubação orgânica semanal com a aplicação de biofertilizante orgânico nas proporções (doses) correspondentes a esses tratamentos. Vale ressaltar, que antes de todos estes procedimentos, foi feito o cálculo para estimar a capacidade de campo do solo utilizado nos vasos, ou seja, o quanto de água poderia ser retido pelo volume de solo contido no vaso, só assim foi possível determinar a quantidade ou o volume "ideal” da solução (água + sobrenadante) que pode ser utilizada por vaso, sem que ultrapassasse sua capacidade de armazenamento de água. Então a partir da determinação da capacidade de campo do solo contido no vaso, foi possível determinar o volume da solução a ser aplicada.

Para enchimento dos vasos, o solo local, classificado como latossolo vermelho-amarelo, foi coletado a uma profundidade $0-20 \mathrm{~cm}$ e misturado com calcário dolomítico (de acordo com a dose recomendada baseada na análise de solo e posteriormente colocado em cada recipiente.

O plantio foi realizado manualmente, onde foram semeadas cinco sementes de feijoeiro por vaso, e dez dias após a germinação e emergência foram desbastadas algumas plântulas, deixando apenas as duas plantas mais vigorosas por vaso. Cada unidade experimental foi constituída de um vaso com duas plantas de feijoeiro, dispostos ao acaso, totalizando 56 unidades experimentais. As amostras de solo local e biofertilizante foram encaminhadas para realização de análises químicas em laboratório de solos especializado. $\mathrm{Na}$ Caracterização química da camada de $0-20 \mathrm{~cm}$ do solo utilizado no experimento este apresentou os seguintes teores de: M.O (mat. org.) $8 \mathrm{dcm}^{-3}$; $\mathrm{pH} \mathrm{4,5;} \mathrm{P}$ (fósforo) $19 \mathrm{mg} \cdot \mathrm{dm}^{-3} ; \mathrm{K}$ (potássio) 1,3 mmolc. $\mathrm{dm}^{-3}$; Ca (cálcio) $14{\mathrm{mmol} . \mathrm{dm}^{-3} ; \mathrm{Mg}}$ (magnésio) 4 mmolc.dm ${ }^{-3}$; S. B. (Soma Bases) 19,3 mmolc. $\mathrm{dm}^{-3} ; \mathrm{H}+\mathrm{Al}$ (ac. potencial) 14 mmolc. $\mathrm{dm}^{-3}$; CTC (cap. troca cat) 33,3 mmolc.dm-3; V\% 58\%. Na análise química do biofertilizante este apresentou os seguintes teores de: nitrogênio total (\%): 0,216; P2O5 (total) (\%): 0,016; K2O solúvel (\%): 0,135 e pH 6,87 .

\section{Parâmetros avaliados na cultura do feijão}

Ao final da sétima semana após a germinação foram coletadas todas as plantas das unidades experimentais correspondentes a cada tipo de tratamento. As variáveis observadas em cada unidade experimental, foram: V1 - Altura média em cm (ALT), V2 - Massa fresca da parte aérea (MFPA), V3 - Massa seca da parte aérea (MSPA), V4 - Massa seca da raiz (MSR), V5 Comprimento de raiz (CR), V6 - Número de folhas / planta (NF) e V7 - Número de nódulos / planta (ND).

\section{Análise estatística}

Para cada uma das variáveis avaliadas (V1, V2, V3...V8) no experimento, foi realizada análise de variância a partir da utilização do programa estatístico ASSISTAT 7.7. (SILVA; AZEVEDO, 2009). Por se tratar de experimento com tratamentos qualitativos foi aplicado o Teste de Tukey ao nível de 5\% de probabilidade.

\section{RESULTADOS E DISCUSSÃO}

A partir da análise de variância verificouse que houve resposta significativa dos tratamentos estudados em nível de $5 \%$ de probabilidade para os seguintes parâmetros avaliados: Altura média em cm (ALT); Massa fresca da parte aérea (MFPA); Massa seca da parte aérea (MSPA); Massa seca da raiz (MSR) e Número de folhas / planta (NF), não havendo efeito significativo para o número de nódulos / planta (ND).

Os tratamentos utilizando doses de biofertilizante apresentaram valores médios superiores para a maior parte dos parâmetros avaliados, exceto, para a variável número de nódulos pelo teste de Tukey a 5\%.

\section{Altura de plantas (ALT)}

A Figura 1 apresenta os valores de altura de plantas (ALT) obtidos pelos diferentes tratamentos. 


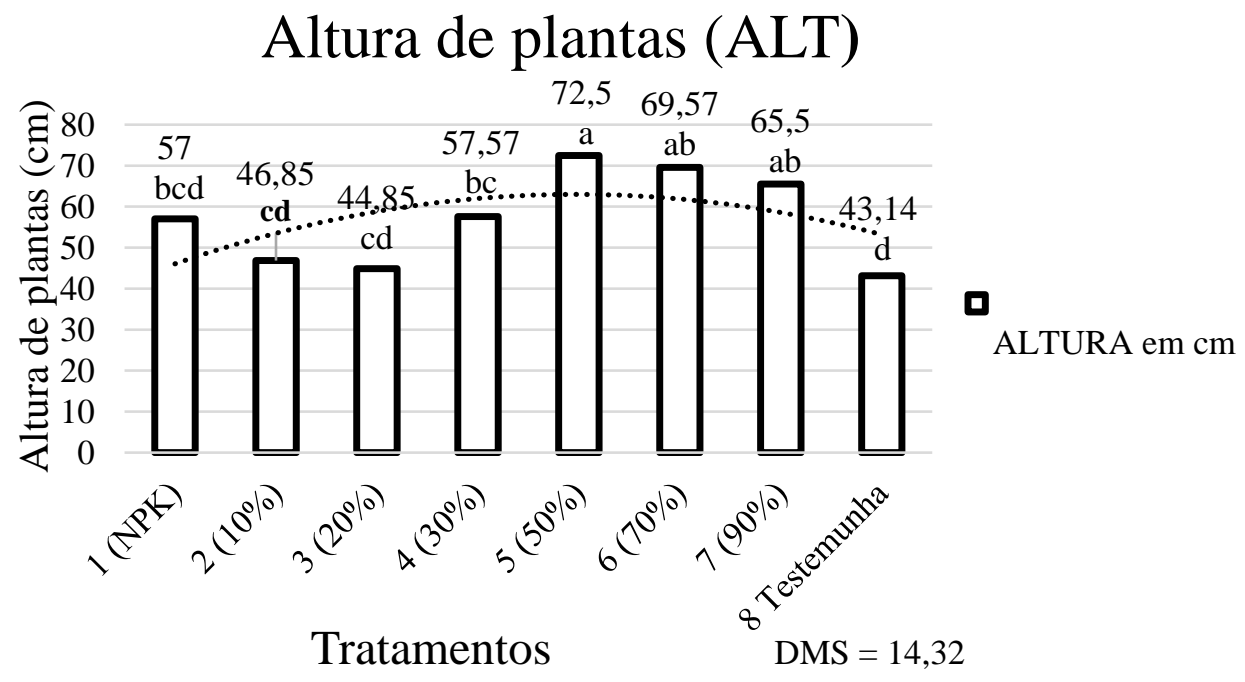

Figura 1. Valores médios de Altura de plantas $(\mathrm{cm})$ obtidos pelos diferentes tratamentos estudados.As médias seguidas pela mesma letra não diferem estatisticamente entre si pelo Teste de Tukey ao nível de $5 \%$ de probabilidade $(\mathrm{P}<0,05)$.

De acordo com a Figura 1 observa-se que a partir da dose de $20 \%$ de biofertilizante observou-se um aumento gradativo da altura de plantas com a dose de biofertilizante, com valor máximo para a dose de $50 \%$ que proporcionou uma altura de $72,5 \mathrm{~cm}$, havendo redução a partir daí, o que pode ser atribuído a sintomas de estresse nutricional que resultou em um decrescimento de altura, por toxidez, devido a relação absorção/concentração excessiva de nutrientes. Resultados semelhantes aos obtidos nesse estudo, também foram verificados por Alves (2009) onde se constataram um decréscimo na altura das plantas de feijão à medida que se aumentou a dosagem de biofertilizante no solo. Efeitos similares foram encontrados nos trabalhos de Souza et al. (2012), estudando diferentes doses de biofertilizante bovino na cultura do feijão caupi, observou-se que as plantas atingiram altura máxima de 75,65 cm quando se utilizou a concentração de 39,80\% de participação do biofertilizante. Barros; Liberalino Filho (2008), em trabalho com composto orgânico sólido e em suspensão na cultura do feijão mungo verde (Vigna radiatal. wilkzeck), também verificaram-se que houve efeito significativo da aplicação de composto orgânico e composto em suspensão para a altura das plantas. O mesmo comportamento também foi verificado por Alves et al. (2009), que observaram efeito significativo da aplicação de diferentes dosagens e concentrações biofertilizante sobre a altura das plantas de feijoeiro.

\section{Massa fresca da parte aérea (MFPA)}

A Figura 2 apresenta os valores de Massa fresca da parte aérea (MFPA) obtidos pelos diferentes tratamentos. 


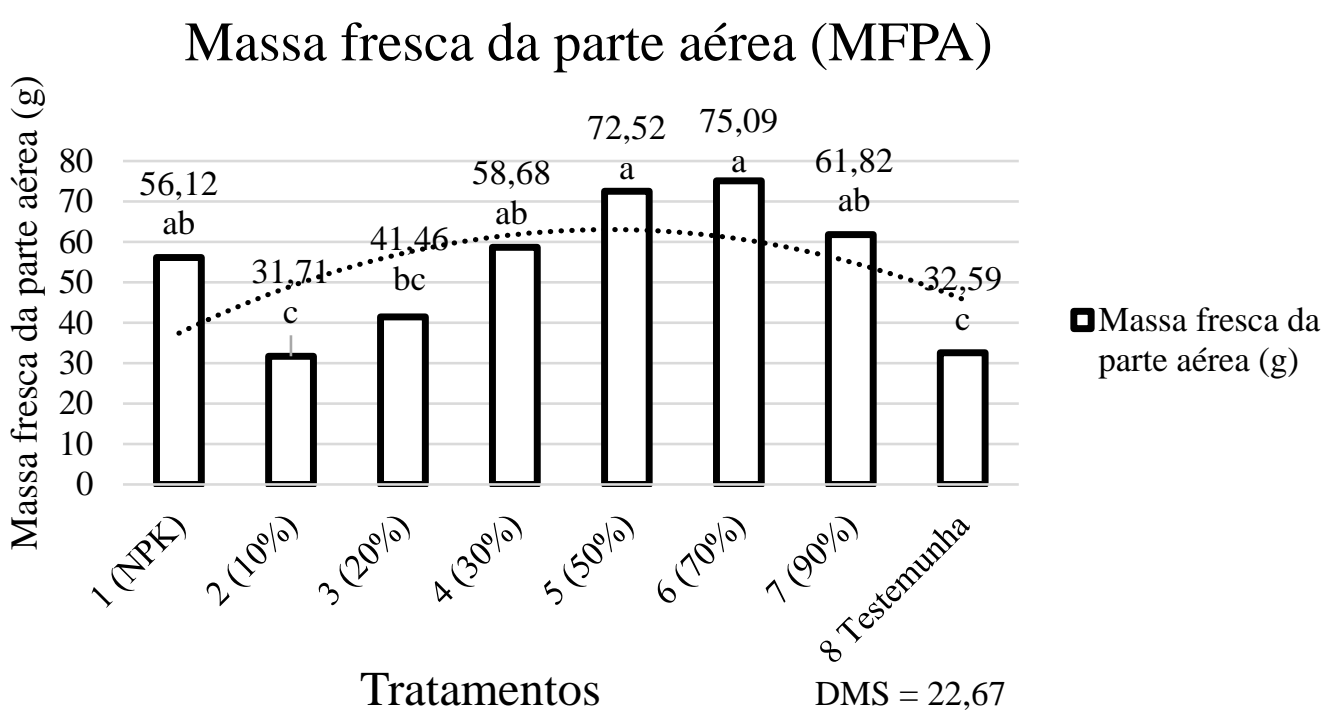

Figura 2. Valores médios de massa fresca da parte aérea obtidos pelos diferentes tratamentos. As médias seguidas pela mesma letra não diferem estatisticamente entre si pelo Teste de Tukey ao nível de $5 \%$ de probabilidade $(\mathrm{P}<0,05)$.

De acordo com a Figura 2 observa-se que a partir da dose de $10 \%$ de biofertilizante observou-se um aumento gradativo da massa fresca da parte aérea de plantas com o aumento dose de biofertilizante, apresentando uma curva de tendência quadrática de comportamento, apresentando valor máximo para a dose de $70 \%$ que proporcionou massa fresca da parte aérea de 75,09 g. Efeitos similares foram encontrados nos trabalhos de Martins et al. (2008) na cultura da beterraba, onde verificaram que as maiores doses de biofertilizante (60 e 90 mL. $\mathrm{L}^{-1}$ ) resultaram em maior massa fresca das plantas, quando comparado com as doses inferiores $(0 \mathrm{e}$ $\left.30 \mathrm{~mL} . \mathrm{L}^{-1}\right)$. A análise do Figura 2 permite verificar que elevadas doses de biofertilizante causaram redução na massa fresca da parte aérea, que pode ser atribuído a sintomas de estresse nutricional que resultou em um decrescimento de massa fresca da parte aérea, provavelmente por toxidez, devido a absorção/concentração excessiva de nutrientes.
Com base nos dados apresentados na Figura 2 também foi possível notar que as tratamentos afetaram significativamente a massa fresca da parte aérea, estando de acordo com os resultados obtidos por Alves et al., (2009), os quais também observaram efeito significativo da aplicação de diferentes dosagens e concentrações biofertilizante sobre a massa fresca da parte aérea das plantas de feijoeiro. Barros; Liberalino Filho (2008), em trabalho com composto orgânico sólido e em suspensão na cultura do feijão mungo verde (Vigna radiatal. wilkzeck), também verificaram que houve efeito significativo da aplicação de composto orgânico e composto em suspensão na massa fresca da parte aérea das plantas.

\section{Massa seca da parte aérea (MSPA)}

A Figura 3 apresenta os valores de massa seca da parte aérea (MSPA) obtidos pelos diferentes tratamentos. 


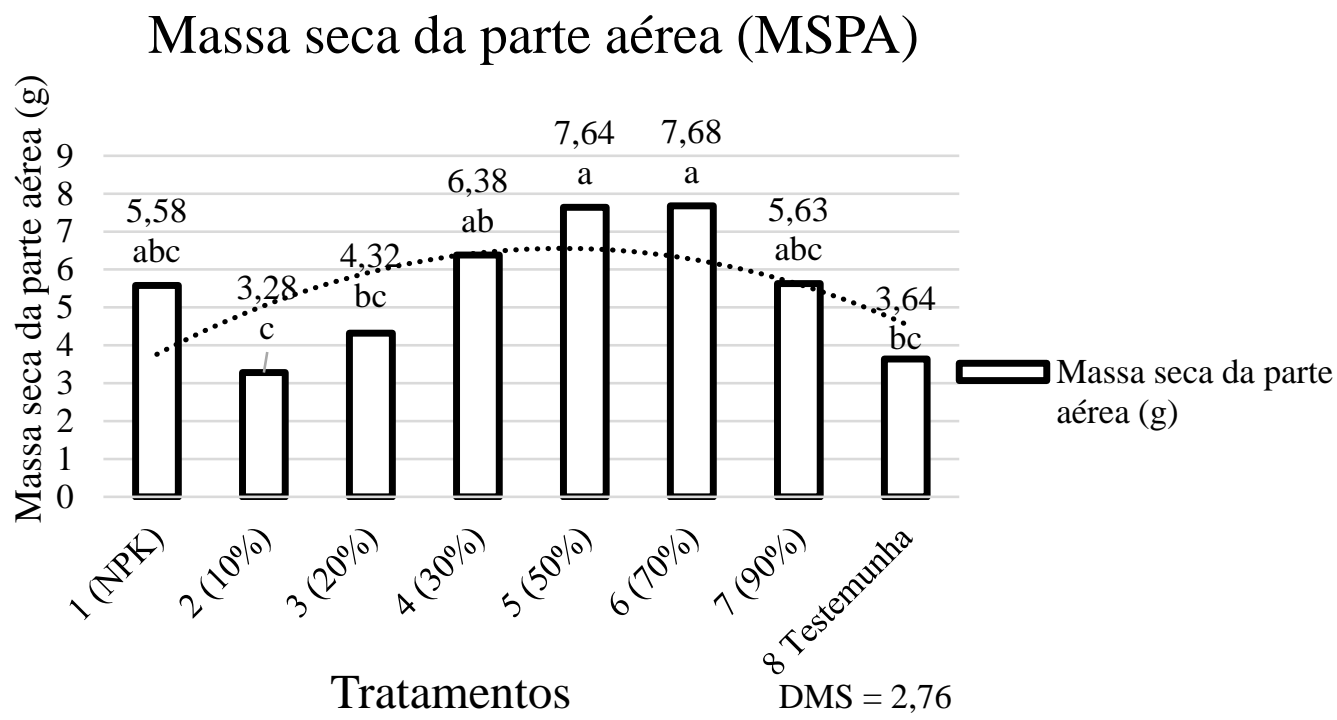

Figura 3. Valores médios de massa seca da parte aérea obtidos pelos diferentes tratamentos. As médias seguidas pela mesma letra não diferem estatisticamente entre si pelo Teste de Tukey ao nível de $5 \%$ de probabilidade $(\mathrm{P}<0,05)$.

De acordo com o Figura 3, observa-se que a partir da dose de $10 \%$ de biofertilizante observou-se um aumento gradativo da massa seca da parte aérea de plantas com a dose de biofertilizante, apresentando uma curva de tendência quadrática de comportamento, com valor máximo para a dose de $70 \%$ que proporcionou o valor de massa seca da parte aérea de 7,68 g, havendo redução a partir daí, que pode ser atribuído a sintomas de toxidez, devido a absorção/concentração excessiva de nutrientes no substrato. Resultados semelhantes aos obtidos nesse estudo, também foram verificados por Souza et al. (2012) onde o autor verificou o aumento na massa seca da parte aérea em função das doses de biofertilizante até a dose máxima de 63,3 L.ha ${ }^{-1} \cdot \mathrm{dia}^{-1}$, com 31,0 g planta $^{-1}$ (massa seca total). Efeitos similares foram encontrados nos trabalhos de Silva et al. (2013), estudando diferentes doses de biofertilizante bovino na cultura do feijão-caupi, o autor também observou que o aumento nas doses de biofertilizante resultou em aumento na massa seca total, em que as plantas atingiram o valor de 31 g.planta ${ }^{-1}$ quando se utilizou a dose máxima de 63,3 $\mathrm{L} \mathrm{ha}^{-1}$ de biofertilizante. A aplicação de biofertilizante no solo, conforme Baalousha et al. (2006), pode induzir aumento no ajustamento osmótico às plantas pela acumulação de solutos orgânicos, promovendo maior absorção de água e nutrientes em meios salinos. Como se depreende do Figura 3, o uso de biofertilizante e da adubação mineral influenciaram significativamente na massa seca da parte aérea, estando de acordo com os resultados obtidos por Galbiatti et al. (2011), os quais também observaram efeito significativo da aplicação de diferentes dosagens e concentrações biofertilizante sobre a massa seca da parte aérea das plantas de feijoeiro. Resultados semelhantes foram encontrados na cultura do capim limão por Blank et al. (2007), em que observaram que as doses de biofertilizante comercial também afetaram de forma significativa a massa seca da parte aérea de plantas. Entretanto o mesmo não foi observado no trabalho de Pereira et al., (2013), estudando a influência do biofertilizante a base de esterco bovino no crescimento de feijão, o autor constatou que os tipos e doses dos biofertilizantes utilizados não afetaram de forma significativa a massa seca da parte aérea do feijoeiro.

\section{Massa seca da raiz (MSR)}

A Figura 4 apresenta os valores de Massa seca da raiz (MSR) obtidos pelos diferentes tratamentos. 


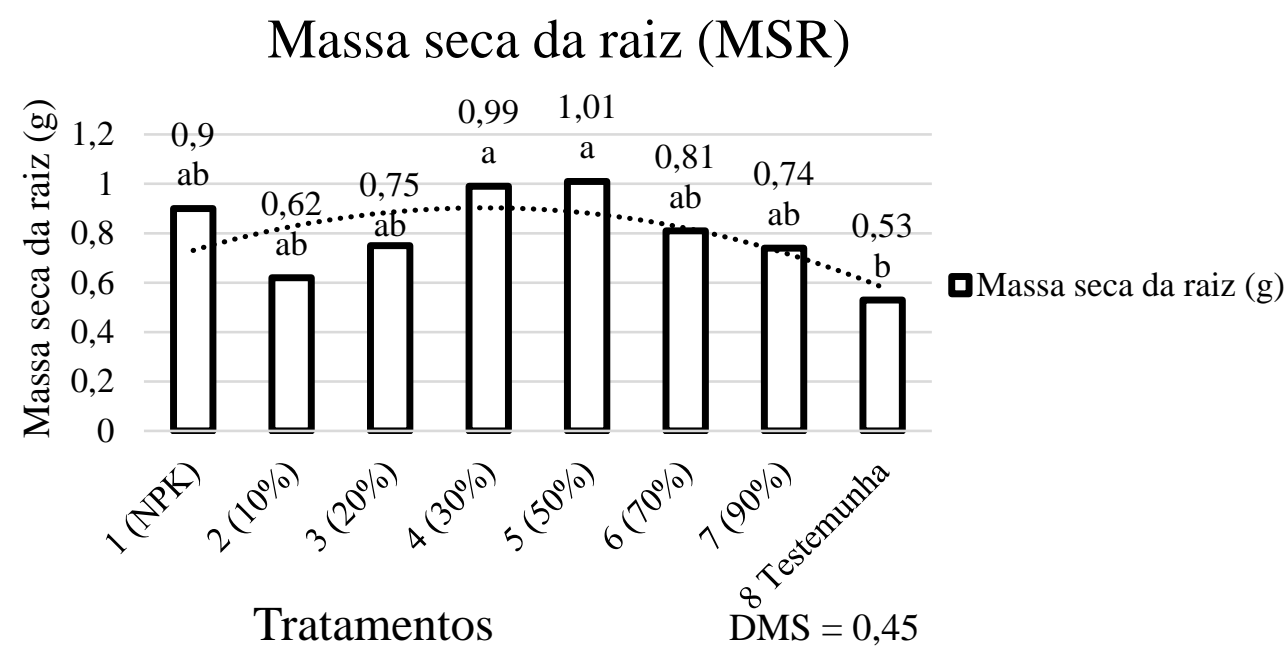

Figura 4. Valores médios de massa seca da raiz obtidos pelos diferentes tratamentos. As médias seguidas pela mesma letra não diferem estatisticamente entre si pelo Teste de Tukey ao nível de $5 \%$ de probabilidade $(\mathrm{P}<0,05)$.

De acordo com o Figura 4, observa-se que a partir da dose de $10 \%$ de biofertilizante observou-se um aumento gradativo da massa seca da raiz com a dose de biofertilizante, ou seja as doses crescentes do biofertilizante favoreceram ao acúmulo de massa seca da raiz e consequentemente maior produção e rendimento de raiz, apresentando uma curva de tendência quadrática de comportamento, com valor máximo para a dose de $50 \%$ que proporcionou a massa seca da raiz de 1,01 g, havendo redução a partir daí, que pode ser atribuído a sintomas de estresse nutricional que resultou em um decrescimento de massa seca da parte raiz, por toxidez, devido a absorção/concentração excessiva de nutrientes. Com base nos dados apresentados no Figura 4 foi possível notar que o uso de biofertilizante e da adubação mineral influenciaram significativamente na massa seca da raiz, os resultados de acordo com os resultados obtidos por Martins (2014), que também observou o efeito significativo da aplicação de biofertilizantes sobre a massa seca da raiz das plantas de feijoeiro. Entretanto o mesmo foi observado por Silva et al. (2013) no qual obteve efeito significativo da interação de tipos de solo e doses de biofertilizante sobre a massa seca das raízes de feijão caupi. Vale ressaltar, que plantas que apresentam maiores valores de matéria seca na raiz, representam plantas mais bem nutridas, com maiores teores radiculares de potássio, fósforo, nitrogênio e outros nutrientes o que pode contribuir para uma maior capacidade de absorção de água e nutrientes devido ao ajustamento osmótico radicular.

\section{Comprimento de raiz (CR)}

A Figura 5 apresenta os valores de comprimento de raiz (CR) obtidos pelos diferentes tratamentos. 


\section{Comprimento da raiz (CR)}

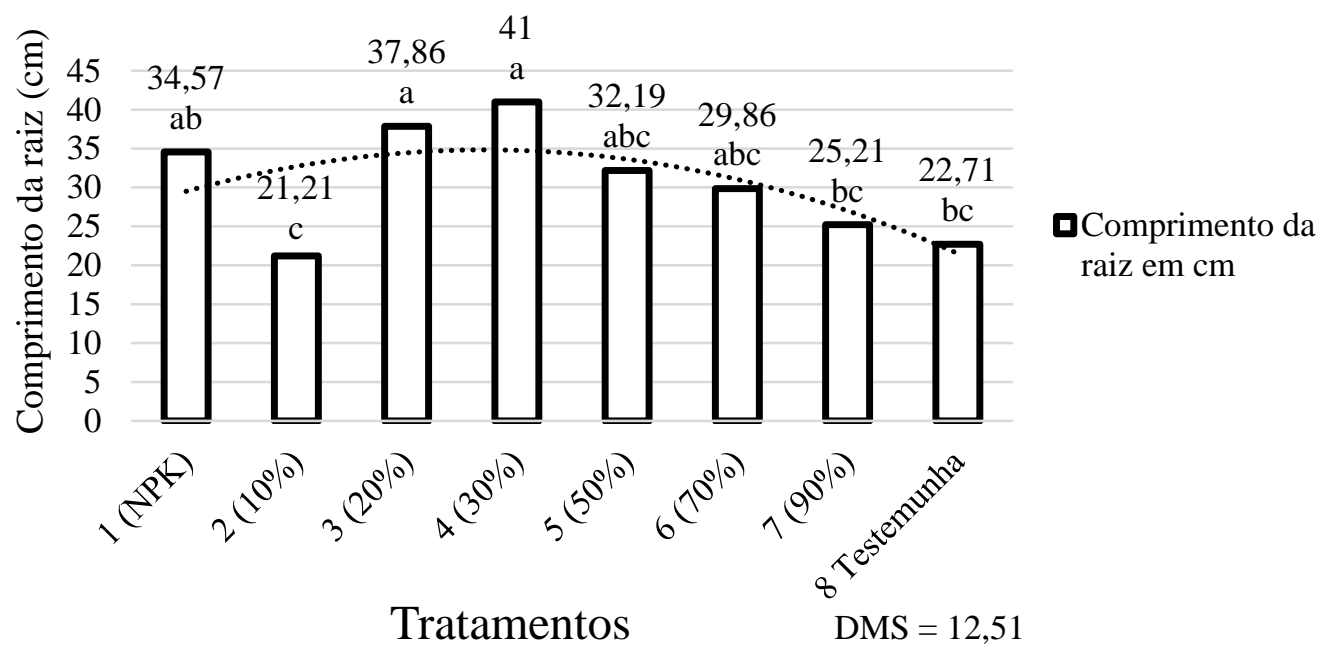

Figura 5. Valores médios de comprimento de raiz obtidos pelos diferentes tratamentos. As médias seguidas pela mesma letra não diferem estatisticamente entre si pelo Teste de Tukey ao nível de $5 \%$ de probabilidade $(\mathrm{P}<0,05)$.

De acordo com o Figura 5, observa-se que a partir da dose de $10 \%$ de biofertilizante observou-se um aumento comprimento da raiz de plantas com a dose de biofertilizante, apresentando uma curva de tendência quadrática de comportamento, com valor máximo para a dose de $30 \%$ que proporcionou um comprimento médio de raiz $41 \mathrm{~cm}$, percebe-se que o parâmetro comprimento de raiz é bastante sensível a altas doses de biofertilizante, concentrações acima de 30\% de biofertilizante resultaram em reduções crescentes no comprimentos de raiz, o que pode ser atribuído a sintomas de estresse nutricional que resultou em um decrescimento do comprimento de raiz, por toxidez, devido a absorção/concentração excessiva de nutrientes. Vale ressaltar, que maiores comprimentos de raiz favorecem a absorção de água e nutrientes em maiores profundidades do solo.

Com base nos dados apresentados na
Figura 5, também foi possível notar que as doses de biofertilizante afetaram significativamente o comprimento da raiz, estando de acordo com os resultados obtidos por Martins (2014), que também observou o efeito significativo da aplicação de biofertilizantes sobre o comprimento da raiz, das plantas de feijoeiro. O mesmo não foi observado por Beltrão Júnior et al. (2012), que verificaram que as dosagens de biofertilizante orgânico não apresentaram efeito significativo sobre o comprimento da raiz de plantas de feijoeiro. O mesmo também foi verificado por Souza (2014) mostrando que os tratamentos não influenciaram nesses aspectos, não corroborando com o comportamento apresentado nessa pesquisa.

\section{Número de folhas por planta (NP)}

A Figura 6 apresenta os valores de número de nódulos por planta (NP) obtidos pelos diferentes tratamentos. 


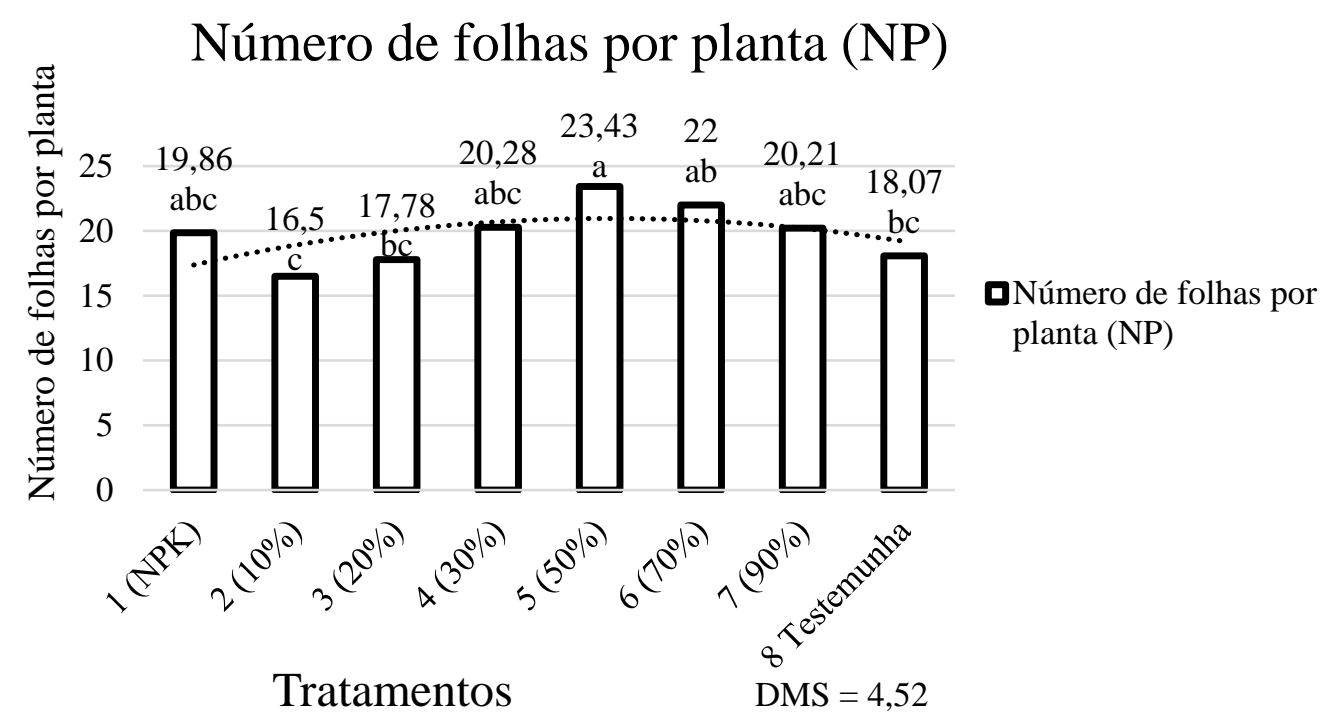

Figura 6. Valores número de folhas por planta obtidos pelos diferentes tratamentos. As médias seguidas pela mesma letra não diferem estatisticamente entre si pelo Teste de Tukey ao nível de $5 \%$ de probabilidade $(\mathrm{P}<0,05)$.

De acordo com o Figura 6, observa-se que a partir da dose de $10 \%$ de biofertilizante observou-se um aumento gradativo número de folhas por planta com a dose de biofertilizante, apresentando uma curva de tendência quadrática de comportamento, com valor máximo para a dose de $50 \%$ que proporcionou número de folhas por planta 23,43 unidades, havendo redução a partir daí, que pode ser atribuído a sintomas de estresse nutricional que resultou em um decrescimento de altura, por toxidez, devido a absorção/concentração excessiva de nutrientes. Os resultados obtidos nesse estudo corroboram com os apresentados por Alves et al., (2009) estudando o desempenho produtivo do feijoeiro em função da aplicação de biofertilizantes, que esta variável apresenta valor superior nas plantas que receberam maiores quantidades de biofertilizante, obtendo maior número de folhas (167) quando aplicouse a dose de $150 \mathrm{~mL} /$ planta/vez. Resultados semelhantes foram obtidos por Silva et al. (2013), os quais também observaram resposta positiva da aplicação de biofertilizante sobre o número de folhas do feijão caupi. Com base nos dados apresentados no Figura 6, também foi possível notar que as doses de biofertilizante afetaram significativamente número de folhas por planta, estando de acordo com os resultados obtidos por Martins (2014), os quais também observaram efeito significativo da aplicação de diferentes dosagens e concentrações biofertilizante sobre número de folhas por planta de feijoeiro.

O número de folhas é importante variável a ser analisada no feijoeiro porque grande parte da massa seca dos grãos é constituída de carboidratos e nitrogênio, e a maior parte deste nutriente está estocada nas folhas sob a forma de proteínas, que na formação de vagens e grãos são mobilizadas e translocadas para estes órgãos (MOREIRA et al., 2003). Este fator pode ser determinante para o potencial produtivo da cultura.

Número de nódulos por planta (NP) 


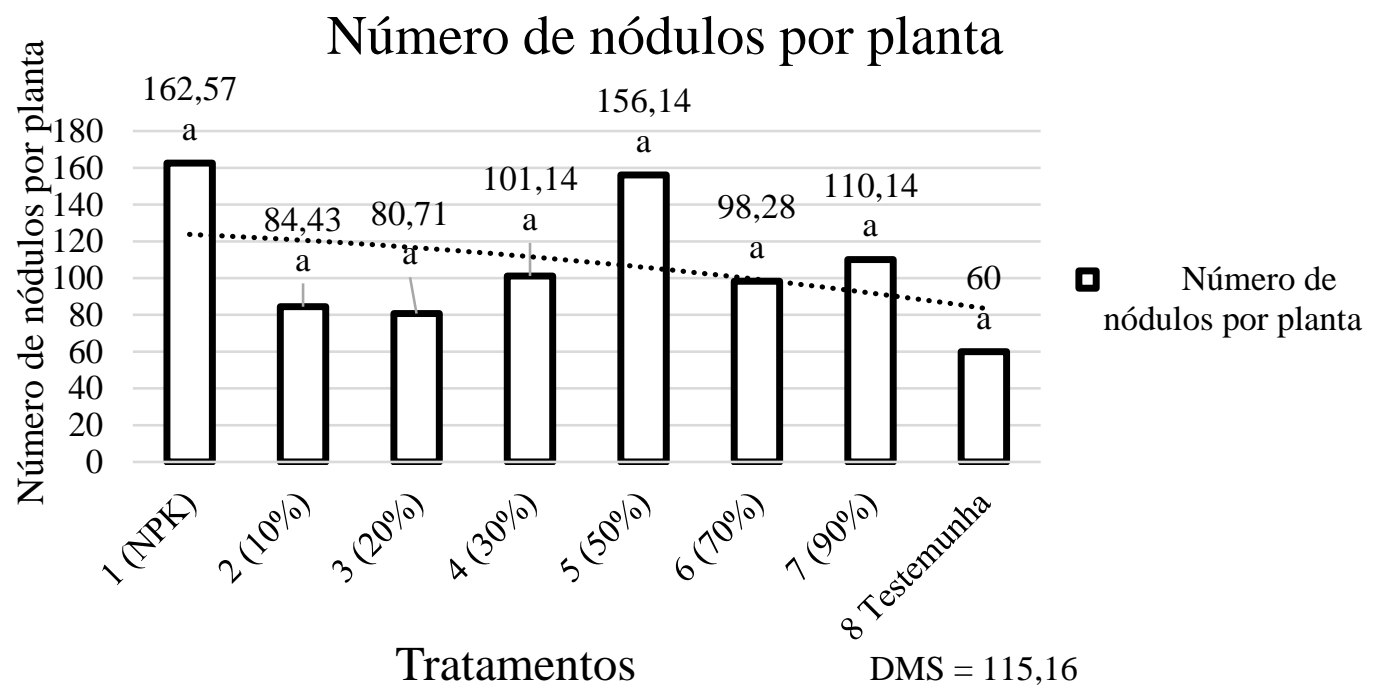

Figura 7. Valores número de nódulos por planta obtidos pelos diferentes tratamentos. As médias seguidas pela mesma letra não diferem estatisticamente entre si pelo Teste de Tukey ao nível de $5 \%$ de probabilidade $(\mathrm{P}<0,05)$.

De acordo com o Figura 7, observa-se que o NPK proporcionou uma maior nodulação nas plantas de feijão caupi. A adubação química favoreceu o processo de nodulação, uma vez que permitiu bons níveis de $\mathrm{P}$ e $\mathrm{N}$ solúvel no solo que são elementos que em quantidades adequadas favorecem a nodulação. Em relação as doses de biofertilizante observa-se que a partir da dose de $20 \%$ de biofertilizante observou-se um aumento gradativo no número de nódulos por planta com a dose de biofertilizante, com valor máximo para a dose de $50 \%$ que proporcionou um número médio de 156,14 nódulos por planta. A baixa nodulação apresentada pela a maioria das doses de biofertilizante em relação ao NPK, pode ser atribuída ao fato que as aplicações semanais de biofertilizante no solo podem ter fornecido $\mathrm{N}$ frequentemente às plantas, fazendo com que elas não necessitassem da associação simbiótica para a obtenção de N. Uma vez que as aplicações constantes de biofertilizantes contribuíram para a elevação dos níveis de nutriente no meio, causando a redução da nodulação. Com base na análise dos dados apresentados no Figura 7, foi possível notar que o NPK e as doses de biofertilizante não afetaram significativamente $o$ número de nódulos por planta ao nível de $5 \%$ de probabilidade, embora havendo grandes variações no número de nódulos com os tipos e doses de fertilizantes utilizados, uma vez que, o número de nódulos variou de 162,57 a 60 unidades, onde os maiores valores foram obtidos nos tratamentos 1 (NPK) e $5 \quad(50 \%$ de biofertilizante), enquanto que os menores valores foram observados nos tratamentos 3 (20\% de biofertilizante) e 8 (testemunha).

\section{CONCLUSÕES}

1- As doses de biofertilizante promoveram aumentos na altura de plantas (ALT), Massa fresca da parte aérea (MFPA), Massa seca da parte aérea (MSPA); Massa seca da raiz (MSR) e Número de folhas / planta (NF), não havendo efeito significativo para o número de nódulos / planta (ND).

3- As doses de $50 \%$ e $70 \%$ de biofertilizante, proporcionaram melhor desempenho, para a maioria das características analisadas.

4- A partir dos resultados obtidos no presente trabalho pode-se concluir que a aplicação do composto orgânico líquido favoreceu aumento de desempenho para a maioria dos parâmetros avaliados no feijão-caupi.

\section{REFERÊNCIAS BIBLIOGRÁFICAS}

ALVES, S. V.; VIEIRA ALVES, S. S.; CAVALCANTI, M. L. F.; DEMARTELAERE, A. C. F.; SILVA TEÓFILO, T. M. de. Desempenho produtivo do feijoeiro em função 
da aplicação de biofertilizantes. Ver.. Verde de Agroecologia e Desenvolvimento Sustentável Grupo Verde de Agricultura Alternativea, v. 4, n. 2, p. 113-117, 2009.

BAALOUSHA, M.; HEINO, M. M.; LE COUSTUMER, B. K. Conformation and size of humic substances: effects of major cation concentration and type, $\mathrm{pH}$, salinity and residence time. Colloids and surfaces. Physicochemical and Engineering Aspects, v.222, n.1-2, p.48-55, 2006.

BARROS, L.E.O.; LIBERALINO FILHO, J. Composto orgânico sólido e em suspensão na cultura do feijao mungo-verde (vignaradiatal. wilkzeck). Revista Verde v.3, n.1, p.114122, 2008.

BARROS, M. A; ROCHA, M. M.; GOMES, R. L. F.; DAMASCENO,K. J. S; NEVES, A.C. Adaptabilidade e estabilidade produtiva de feijao-caupi de porte semiprostrado. Pesquisa agropecuária brasileira v.48, n.4, p.403-410, 2013.

BLANK, A. F.; ARRIGONI-BLANK M. F.; AMANCIO V. F.; MENDONÇA M. C.; SANTANA FILHO L. G. M.; 2007. Densidades de plantio e doses de biofertilizante na produção de capim-limão. Horticultura Brasileira . v. 25, n. 3, 343-349, 2007.

BELTRÃO JÚNIOR, J. A.; CRUZ, J. S.; SOUSA, E. C.; SILVA, L.A. Rendimento do feijão-caupi adubado com diferentes doses de Biofertlizante orgânico produzido através da biodegadação Acelerada de resíduos do coqueiro no município de Trairí - CE. Irriga, Edicão Especial, p. 423 - 437, 2012.

BUCHER, C. A.; REIS, V. M. Biofertilizante contendo bactérias diazotróficas. Embrapa Agrobiologia. Documentos, 2008. Disponível em: < http://agris.fao.org/agrissearch/search.do?recordID=BR20081630315> Acessado em: 9 Set. 2018.

COMPANHIA NACIONAL DE ABASTECIMENTO - $\quad$ CONAB.
Acompanhamento da safra brasileira de grãos: 2017/2018, V. 5 - SAFRA 2017/18- N. 4 - Quarto levantamento | JANEIRO 2018. Brasília, DF: Conab, 2018. 126 p. Disponível em:

http://www.agricultura.gov.br/noticias/safra-degraos-podera-atingir-227-9-milhoes-detoneladas-em-2017-

2018/AcompanhamentodaSafraBrasileiradeGro s4Levantamento20172018.pdf> Acessado em: 9 Set. 2018.

CLIMATE-DATA. Clima: Governador Edison Lobão, 2018. Disponível em: < https://pt.climate-data.org/america-dosul/brasil/maranhao/governador-edison-lobao42368/> Acessado em: 9 Set. 2018.

FREIRE FILHO, F.R. (Ed.). Feijão-caupi no Brasil: produção, melhoramento genético, avanços e desafios. Embrapa Meio-Norte, 2011. 84p.

GALBIATTI, J. A.; DA SILVA, F. G.; FRANCO, C. F.; CARAMELO, A. D.; Desenvolvimento do feijoeiro sob o uso de biofertilizante e adubação mineral. Engenharia Agrícola, v.31, n.1, p.167-177, 2011.

MAPA. Projeções do Agronegócio: Brasil 2012/2013 a 2022/2023. Assessoria de Gestão Estratégica. MAPA, 2013. 96p.

MARTINS, J. D. L. Produção e qualidade fisiológica de sementes de feijão comum com aplicação de inoculante, adubação orgânica e mineral. Dissertação (Mestrado em Produção Agrícola) - Universidade Federal Rural de Pernambuco-Unidade Acadêmica de Garanhuns, 2014. f.67.

MARTINS, P. F. R. B.; WAKUGAWA, K. L. M.; AJALA, I. V. S.; MARTINS, R. P.; PEDRINHO, D. R.; WOLSCHICH, D.; SCHLEDER, E. J. D.; RODRIGUES, A. P. C. D. A. Avaliação de mudas de beterrraba em função de diferentes doses de biofertilizante Manejo de Agroecossistemas Sustentáveis Revista Brasileira de Agroecologia - Vol. 3 Suplemento 118 especial, 2008.. 
MOREIRA, J. A. A.; STONE, L. F.; BIAVA, M. Feijão: o produtor pergunta, a Embrapa responde. Embrapa Informação Tecnológica, 2003. p. 39-54.

PEREIRA, R. F.; CAVALCANTE, S. N.; LIMA, A. S.; MAIA FILHO, F. C. F.; SANTOS, J. G. R. Crescimento e rendimento de feijão vigna submetido à adubação orgânica. Revista Verde, v. 8, n. 3, p. 91 - 96, 2013.

RODOLFO JUNIOR, F.; CAVALCANTE, L.F.; BURITI, E. de S. Crescimento e produção do maracujazeiro- amarelo em solo com biofertilizantes e adubação mineral com NPK. Caatinga, v.21, n.2, p.149-160, 2009.

RUMJANEK, N. G.; MARTINS, L. M. V.; XAVIER, G. R.; NEVES, M. C. P. Fixação biológica do nitrogênio. In: FREIRE FILHO, F. R.; LIMA, J. A. A.; RIBEIRO, V. Q. (Ed.) Feijão-caupi: avanços tecnológicos. Embrapa, 2005. p.281-335.

SEDIYAMA, M.A.N; SANTOS, M.R.; VIDIGAL, S.M.; PINTO, C.O.; Jacob, L.L.Nutrição e produtividade de plantas de pimentão colorido, adubadas com biofertilizante de suíno. Revista Brasileira de Engenharia Agrícola e Ambiental, v.18, n.6, p.588-594, 2014.

SILVA, F. de A. S.; AZEVEDO, C. A. V. de. Principal Components Analysis in the Software Assistat-Statistical Attendance. In: WORLD CONGRESS ON COMPUTERS IN AGRICULTURE, 7, Reno-NV-USA: American Society of Agricultural and Biological Engineers, 2009.
SILVA, J. A.; OLIVEIRA, A. P.; ALVES, G. D. S.; CAVALCANTE, L. F.; OLIVEIRA, A. N. P. de; ARAÚJO, M. A. M. Rendimento do inhame adubado com esterco bovino e biofertilizante no solo e na folha. Revista Brasileira de Engenharia Agrícola e Ambiental, v. 16, n. 3, p. 253-257, 2012.

SILVA, M. L. N.; OLIVEIRA, F. A.; OLIVEIRA, M. K. T.; MAIA, P. M. E.; SILVA, R. C. P.; SILVA, O. M. P. Efeito de biofertilizante bovino aeróbico na cultura do feijão caupi. Revista ACSA. V. 9, n. 1, p. 110116, jan ./ mar., 2013.

SILVA, O. F.; WANDER, A. E. O feijãocomum no Brasil: Passado, Presente e Futuro. EMBRAPA-CNPAF, 2013. 63p. (EMBRAPACNPAF. Documentos, 287).

SOUZA, J. A. de. Efeitos da quantidade de húmus da minhoca e fertilizantes orgânicos na cultura do feijão caupi. 2014. 39f. Trabalho de Conclusão de Curso (Graduação em Ciências Agrárias) - Universidade Estadual da Paraíba, 2014.

SOUZA, M. W. L.; $\quad$ SILVA, R. T.; NETA, M. L. S.; MEDEIROS, R. C. A.; MARTINS, D. C.; OLIVEIRA, F. A.; SILVA, M. L. N. Desenvolvimento inicial de plantas de feijão cultivadas em dois tipos de solo e submetidas a doses de composto orgânico líquido. In: CONGRESSO NACIONAL DE FEIJÃO CAUPI. Anais... Disponível em: <www.conac2012.org>. Acesso em: 20 dezembro 2016. 